Revista Tecnologia e Sociedade, Curitiba, v. 11, n. 23, 2015

ISSN (versão online): 1984-3526

ISSN (versão impressa): 1809-0044

\title{
A cidade média interiorizada: Pau dos Ferros no desenvolvimento regional $^{1}$
}

The medium-sized town interiorized: Pau dos Ferros in regional development

\author{
Joseney Rodrigues de Queiroz Dantas ${ }^{2}$ \\ Maria do Livramento Miranda Clementino ${ }^{3}$ \\ Rosana Silva de França ${ }^{4}$
}

Artigo submetido em ago./2015 e aceito para publicação em set./2015.

\section{RESUMO}

Este trabalho insere-se no estudo das cidades médias e seu papel no desenvolvimento regional e urbano e tem como objetivo compreender os determinantes da produção do espaço urbano-regional de Pau dos Ferros (RN). O fio condutor da análise foi o modo como vem se reconfigurando as cidades médias interiorizadas e como essa reconfiguração afeta as relações entre as cidades e entre as cidades e as regiões. Pau dos Ferros vem desempenhando na sua área de influencia as funções de intermediação, na oferta dos serviços de educação superior e saúde, além da oferta de empregos. Essa realidade se estende a outros centros sub-regionais no interior do nordeste, que em virtude da recente interiorização dos serviços públicos, têm dinamizado sua economia e têm ampliado sua área de influência. São cidades integradas à dinâmica da urbanização regional que necessitam da continuidade da descentralização dos investimentos federais considerados estratégicos para o desenvolvimento regional.

Palavras-chave: Cidade Média. Desenvolvimento Regional. Pau dos Ferros.

\begin{abstract}
This work is part of the study of medium-sized towns and their role in regional and urban development and aims to understand the determinants of production of urban-regional space Pau dos Ferros (RN). The thread of the analysis was the way has been reconfiguring the medium-sized towns interiorized and how this reconfiguration affect relations between cities and between cities and regions. Pau dos Ferros has played in their area of influence intermediation functions in the provision of higher education and health services and the supply of jobs. This reality extends to other sub-regional centers in the interior northeast, that because of recent internalization of public services, have boosted their economy and have expanded its area of influence. Towns are integrated into the dynamics of regional urbanization in need of continued decentralization of federal investments considered strategic for the regional development.
\end{abstract}

Key-words: Medium-sized town. Regional development. Pau dos Ferros.

\footnotetext{
${ }^{1}$ Este artigo foi recortado da Tese de Doutorado "AS CIDADES MÉDIAS NO DESENVOLVIMENTO REGIONAL: um estudo sobre Pau dos Ferros/RN", defendida em março de 2014, no Programa de Pós-Graduação em Ciências Sociais (UFRN), autoria de Joseney Rodrigues de Queiroz Dantas e orientação da Profa. Maria do Livramento Miranda Clementino.

2 Doutora em Ciências Sociais (UFRN); Coordenadora do Programa de Pós-Graduação em Planejamento e Dinâmicas Territoriais no Semiárido (PLANDITES/UERN); Líder do Grupo de Estudos e Pesquisas em Economia, Cultura e Território (GEPECT). joseneyqueiroz.uern@gmail.com

${ }^{3}$ Doutora em Economia (UNICAMP) com PHD-Université Paris; Docente Permanente do Programa de PósGraduação em Estudos Urbanos e Regionais (PPEUR/UFRN);Coordenadora do Núcleo RMNatal - Observatório das Metrópoles. clement@ufrnet.br

4 Doutoranda em Ciências Sociais-UFRN; Docente CERES/UFRN; Pesquisadora do Núcleo RMNatal Observatório das Metrópoles. zanafranca@gmail.com
} 
Revista Tecnologia e Sociedade, Curitiba, v. 11, n. 23, 2015

ISSN (versão online): 1984-3526

ISSN (versão impressa): 1809-0044

\section{INTRODUÇÃO}

Este trabalho insere-se no estudo das cidades médias brasileiras (e nordestinas) e seu papel no desenvolvimento regional e urbano. No Brasil, a aceleração do processo de urbanização a partir dos anos 1960, bem como a consequente reorganização do sistema urbano se deu sob o impacto da industrialização com todas as características de um país periférico Faria (1978); Cano (1998); Brandão (2007).

O estudo "Características e Tendências da rede urbana brasileira", publicado pelo Instituto de Pesquisa Econômica Aplicada (IPEA), em 2002, destaca que a malha urbana no eixo litorâneo não sofreu grandes alterações durante o período de desconcentração produtiva da economia brasileira, apesar dos movimentos em direção à expansão das fronteiras agrícola e mineral, fenômeno corroborado pelo último estudo do Instituto Brasileiro de Geografia e Estatística (IBGE) sobre cidades, intitulado Região de Influência das Cidades (REGIC), publicado em 2008. Tratandose do Nordeste, observa-se a existência de uma rede urbana com dupla dinâmica, na qual se identificam características bastante diversas: no litoral a rede urbana é composta pelas capitais dos estados e seu entorno, onde se concentram as atividades mais dinâmicas e os serviços tidos como superiores; no interior, a rede urbana é dispersa e atomizada formada por 'antigas capitais regionais' ${ }^{5}$ e poucos centros que, apesar do baixo dinamismo, desempenham papel importante na dinâmica regional.

É a partir da existência de uma rede urbana desigual em nível de Brasil e que apresenta dupla dinâmica no Nordeste que surge nosso interesse pelos estudos sobre as cidades médias na atualidade. Aqui serão priorizados estudos e reflexões que valorizem os aspectos qualitativos relacionais e estratégicos e que destaquem o papel de intermediação das 'cidades médias' no desenvolvimento regional. Ferrão, Henriques e Neves (1994); Torné y Sanfeliu (2000); Sposito (2001), Araújo, Moura e Dias (2011).

Esses estudos consideram, na definição das cidades médias/intermediárias, os contextos territoriais e socioeconômicos dos diversos estados e nações, bem

\footnotetext{
${ }^{5}$ Andrade (1987); Cano (1989).
} 
Revista Tecnologia e Sociedade, Curitiba, v. 11, n. 23, 2015

ISSN (versão online): 1984-3526

ISSN (versão impressa): 1809-0044

como o papel de intermediação entre as grandes áreas urbanas e os amplos espaços rurais que estão em sua área de influência.

No Brasil, essas característícas de intermediação têm se acentuado em virtude da recente interiorização dos serviços públicos em especial da interiorização da educação superior e da descentralização dos serviços de saúde, os quais tem contribuído para a atração de investimentos privados nas respectivas áreas, para a dinamização da economia dessas cidades e para a ampliação da sua área de influência.

Nessa perspectiva, o objetivo deste trabalho é compreender os principais aspectos da produção do espaço urbano-regional do município de Pau dos Ferros (RN) na 'rede urbana nordestina interiorizada', com fins a refletir sobre o papel das cidades médias no desenvolvimento regional.

Pautamos essa pesquisa não apenas na importância econômica da cidade de Pau dos Ferros ou de suas funções urbanas para o Rio Grande do Norte, mas também discutimos como essa cidade se relaciona com a sua região de influência e com outras cidades, cujos principais indicadores utilizados são: a área de atuação da Universidade do Estado do Rio Grande do Norte (UERN) e do Hospital Regional; e a mobilidade pendular para trabalho e estudo.

A hipótese é que a despeito de um contingente populacional pequeno, em comparação com as cidades classificadas como Médias nos diversos estudos realizados no âmbito nacional, Pau dos Ferros vem desempenhando na rede urbana do Nordeste e, particularmente, do Rio Grande do Norte, as funções de intermediação, na oferta dos serviços de educação superior e saúde, além da oferta de empregos, notadamente no comércio e nos serviços públicos, o que nos permite tratá-la à priori como uma cidade intermediária.

A metodologia aqui utilizada envolve os instrumentos, as técnicas e as dinâmicas que permitem uma (re)leitura crítica da realidade, mediada pelos processos de identificação, registro, coleta, produção, sistematização, análise, interpretação e socialização de informações e dados. Em termos teóricos, partimos da proposta de estudo e do pensamento de autores como Faria (1978) e Brandão (2007), para os quais o estudo do urbano exige a análise de situações concretas a partir de objetos teóricos bem definidos. 
Revista Tecnologia e Sociedade, Curitiba, v. 11, n. 23, 2015

ISSN (versão online): 1984-3526

ISSN (versão impressa): 1809-0044

Considerando a cidade de Pau dos Ferros e o seu papel de centro sub regional (IBGE, 2008), trabalhamos com a proposta de estudar a produção do urbano-regional, como produto de uma dinâmica socioeconômica que transcede os limites do urbano, numa perspectiva histórico-espacial que leve em consideração as relações entre a cidade e a região. Diante disso, o fio condutor da nossa análise foi o modo como vem se reconfigurando as cidades médias interiorizadas na hierarquia dos lugares e como essa reconfiguração afeta de modo diferente as relações entre as cidades e entre as cidades e as regiões.

A coleta de dados foi feita no sítio do IBGE (REGIC, Censos demográficos) e nos arquivos da UERN e das unidades de saúde. A análise e interpretação dos dados foi feita de acordo com o aporte teórico-metodológico norteador da pesquisa, qual seja a análise de situações concretas, o estudo de áreas urbanas específicas, sem perder de vista a posição e as funções que esta área desempenha no interior desse complexo sitema urbano.

\section{AS CIDADES MÉDIAS NO DESENVOLVIMENTO REGIONAL: UM OLHAR SOB A PERSPECTIVA DA 'REDE URBANA NORDESTINA INTERIORIZADA'.}

Ao tratar da urbanização do Nordeste, Cano (1989) aponta a existência de cerca de 20 cidades de porte médio, em sua maioria interiorizadas. Para os objetivos deste estudo, destacamos entre as "antigas" capitais regionais, as cidades de Mossoró-RN, Campina Grande-PB, e Juazeiro do Norte-CE. Atualmente, essas cidades constituem-se capitais regionais com atuação importante na dinâmica econômica-espacial não apenas no nível regional e nacional, mas também no âmbito internacional.

Em um nível abaixo das capitais regionais, na hierarquia urbana, mas de fundamental importância para a rede urbana nordestina interiorizada, estão as cidades classificadas pelo REGIC como Centro Sub-regional ${ }^{6}$, categoria em que se encontra a cidade de Pau dos Ferros/RN. Em virtude da urbanização esparsa e fragmentada no interior do Nordeste, alguns desses centros sub-regionais assumem as funções de intermediação entre os grandes centros e as pequenas cidades.

\footnotetext{
${ }^{6}$ Integram os centros sub-regionais 169 centros com atividades de gestão menos complexas entre os níveis 4 e 5 da gestão territorial, tem área de atuação mais reduzida e presença mais adensada nas áreas de maior ocupação do Nordeste e do Centro Sul. (IBGE, 2008).
} 
Revista Tecnologia e Sociedade, Curitiba, v. 11, n. 23, 2015

ISSN (versão online): 1984-3526

ISSN (versão impressa): 1809-0044

É na perspectiva de que a intermediação é uma das principais caracterísiticas dessas cidades que uma gama de autores, em especial, autores europeus, têm proposto a utilização do termo cidade intermédia ou cidade intermediária, em cujo escopo está embutido critérios de natureza qualitativa, dentre eles a idéia de um espaço de relações estruturados em nós e fluxos. Ferrão, Henriques e Neves (1994); Torné y Sanfeliu (2000); entre outros.

No Brasil, alguns autores também enfatizam a função de centro intermediário exercida pelas cidades médias. De acordo com Amorim Filho e Serra (2001), as cidades médias continuam a ser valorizadas como fator de equilíbrio para as redes e hierarquias urbanas, bem como por exercer as funções de relação e intermediação com as grandes cidades e com as pequenas cidades e o meio rural. Para os autores, o papel de articulação e intermediação são fundamentais para a implantação, desenvolvimento e a expansão dos corredores de transporte e comunicações.

Araujo, Moura e Dias (2011) propõem a necessidade de pensar as cidades médias como unidades articuladas a sistemas de cidades que adensam fluxos de relações materiais e imateriais e que conferem complexidade a funções e papéis específicos, ao mesmo tempo que ampliam a rede de abrangência de sua influência.

De acordo com Pereira (2007), um estudo que se propõe a pensar a cidade intermédia em sua relação com a região implica uma análise das relações, fluxos e processos que condicionam a produção da cidade bem como seu papel regional.

É nesta perspectiva que tratamos das relações estabelecidas entre Pau dos Ferros e região, com destaque para a procura dos serviços públicos de educação superior e saúde, e de emprego.

O primeiro estudo do IBGE, sobre a rede urbana "Divisão do Brasil em regiões Funcionais", publicado em 1972, já destacava a importância das cidades na prestação de serviços essenciais como educação e saúde para a população de toda uma região, bem como o impacto que as diferenças regionais tinham na organização das redes urbanas e destacava a existência de uma rede urbana desorganizada e esgarçada no Norte-Nordeste, com metrópoles regionais hipertrofiadas e centralizadoras e poucos centros regionais subequipados, ligados a um grande número de pequenos centros locais ligados, em sua maioria às atividades tradicionais do meio rural. O IBGE (2008) apresenta poucas mudanças no que se 
Revista Tecnologia e Sociedade, Curitiba, v. 11, n. 23, 2015

ISSN (versão online): 1984-3526

ISSN (versão impressa): 1809-0044

refere aos principais centros e aponta que, a rede urbana no Nordeste continua truncada, com a ausência de alguns níveis intermediários e a concentração de bens e serviços nas capitais estaduais. $O$ destaque fica por conta de alguns centros subregionais, que assumem as funções de intermediação na rede urbana nordestina interiorizada, o que Simões e Amaral (2011) denominam 'novas centralidades urbanas'.

Muitas dessas 'novas centralidades', especialmente as localizadas no semiárido, têm como elemento dinamizador, o setor público, inicialmente com os aposentados e funcionários públicos que juntamente com a cota do Fundo de Participação dos Municípios (FPM), ajudam a criar o que Gomes (2001) denomina 'economias sem produção'. Posteriormente, com as recentes políticas de interiorização da educação superior e da descentralização/regionalização do Sistema Único de Saúde (SUS) essa situação se altera, com a ampliação da participação do emprego nas áreas de educação e saúde no emprego público total. Araújo e Lima (2009).

Consideramos que a atuação dessas duas políticas tem beneficiado de forma direta as cidades médias do interior nordestino, uma vez que os investimentos públicos atraem também os investimentos privados e ajudam a dinamizar a economia dessas cidades. E é a partir dessa perspectiva que este artigo apresenta a dinâmica urbano-regional de Pau dos Ferros-RN, cidade encravada no semiárido nordestino, e seu papel no desenvolvimento regional.

\section{A CIDADE MÉDIA INTERIORIZADA: PAU DOS FERROS NO DESENVOLVIMENTO REGIONAL}

Mesmo que a priori, Pau dos Ferros, não apresente as características tradicionais de uma cidade média, sua localização (fronteiriça e no cruzamento das BR-405 com a BR-226) reforça a sua influência no desenvolvimento regional, que se expande através da oferta de serviços públicos, em especial educação de nível superior e saúde, e reforça suas funções urbanas, com a ampliação de sua área de influencia para além dos limites do Rio Grande do Norte. É comum tratar Pau dos Ferros como uma 'cidade de fronteira' ou 'cidade fronteiriça'. 
Revista Tecnologia e Sociedade, Curitiba, v. 11, n. 23, 2015

ISSN (versão online): 1984-3526

ISSN (versão impressa): 1809-0044

Diante das restrições político-administrativas vinculadas à noção de fronteiras internas (entre estados federados) para um estudo em que a dimensão espacial é norteadora do desenvolvimento regional, tornou-se necessário construir uma "Raia" para denominar essa região. Para a construção da Raia Divisória foi retomada a configuração das antigas capitais regionais nordestinas, constituídas pelo Triângulo Mossoró (RN), Campina Grande (PB) e Juazeiro do Norte (CE), onde as "cidades médias" Cajazeiras (PB), Sousa (PB) e Pau dos Ferros (RN) desempenham funções urbanas importantes ainda hoje ${ }^{7}$.

A Raia Divisória Rio Grande do Norte-Paraíba-Ceará será composta pelos municípios que são 'cortados' pelas rodovias federais que perpassam o interior dos estados do Rio Grande do Norte, Paraíba e Ceará (BR-405, BR-226, BR-230 e BR116) e/ou que estão no interior do 'retângulo' formado pelo encontro dessas rodovias. Pau dos Ferros, nosso locus de estudo, está localizado no interior desse retângulo, mais precisamente na intersecção das BR-405 e BR-226, o que permite a cidade constituir-se num entroncamento de vias de circulação e nó de tráfego ${ }^{8}$, envolvendo pessoas, capitais, informações, mercadorias e serviços.

\footnotetext{
${ }^{7}$ Os critérios utilizados para a construção da Raia Divisória RN-PB-CE podem ser encontrados em Dantas e Clementino (2013) e Dantas (2014).

${ }^{8}$ Os nós de tráfego surgem nos pontos em que se cruzam dois eixos de desenvolvimento, podendo ocorrer até onde existe o cruzamento de duas simples estradas. (ANDRADE, 1973, p. 60).
} 
Revista Tecnologia e Sociedade, Curitiba, v. 11, n. 23, 2015

ISSN (versão online): 1984-3526

ISSN (versão impressa): 1809-0044

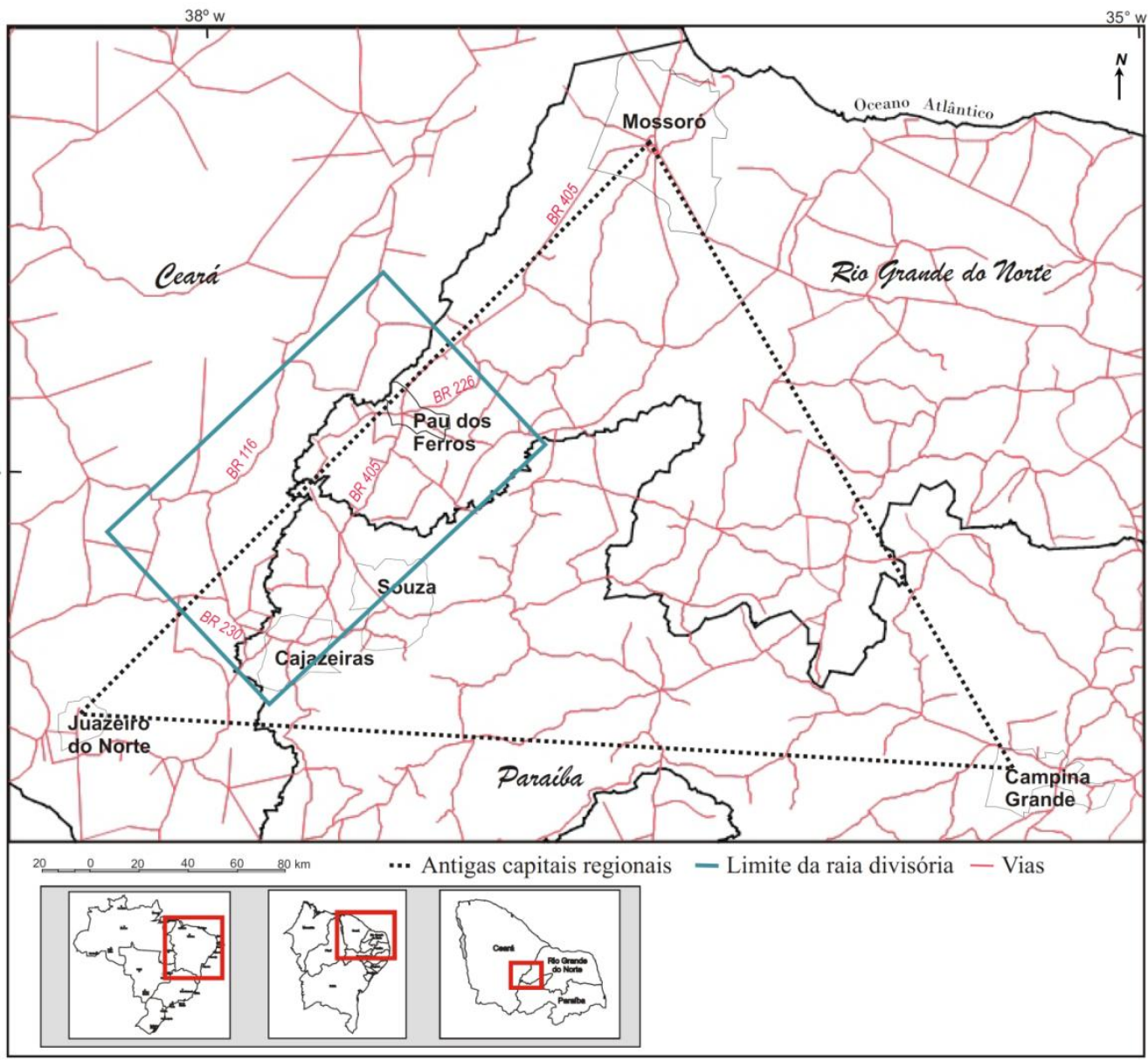

Mapa 1 - A Raia Divisória RN-PB-CE formada pelos entroncamentos viários Fonte: Dantas (2014, p. 135).

A ausência de alguns níveis na hierarquia urbana, característica da rede urbana nordestina, em especial, da interiorizada, faz com que os centros urbanos existentes, apesar de poucos, exerçam forte polarização em suas áreas de influência, as quais tendem a ser bem abrangentes.

Os critérios utilizados para a definição da área de influência de Pau dos Ferros, foram: 1) os dados de relacionamentos do REGIC (IBGE, 2008); 2) os dados de origem residencial dos alunos matriculados nos cursos de graduação do Campus da UERN em Pau dos Ferros (2010-2012) e; 3) os municípios localizados num raio de $100 \mathrm{~km}$ formado a partir da sede do município de Pau dos Ferros. A partir da utilização desses critérios, a área de estudo ficou, portanto, configurada, e passa a ser composta por Pau dos Ferros, e, 55 municípios (42 no Rio Grande do Norte, 09 na Paraíba e 04 no Ceará) conforme mapa 2, a seguir. 

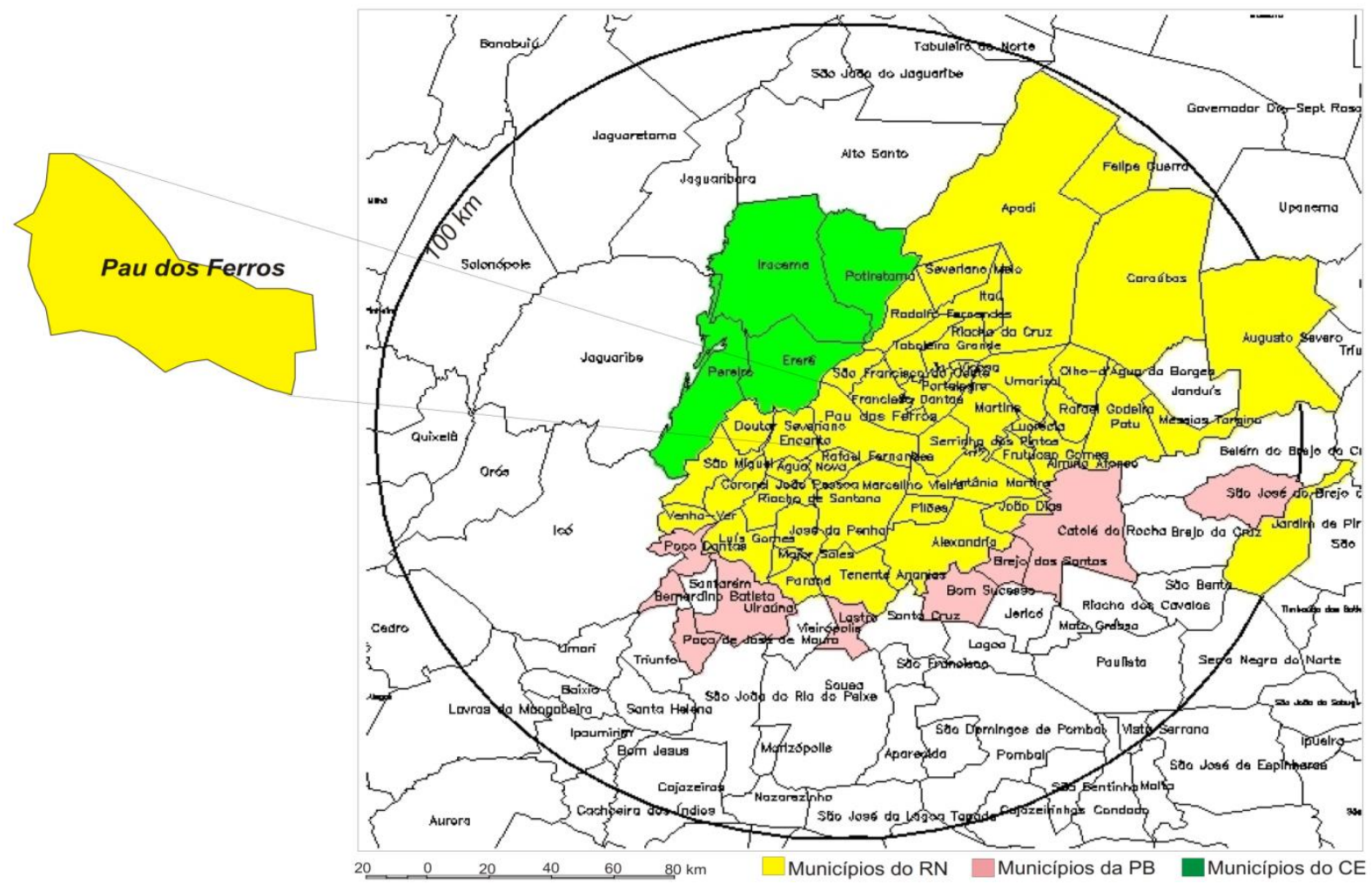

Mapa 2 - Área de influência de Pau dos Ferros

Fonte: Dantas (2014, p. 194).

Somadas as populações desses municípios, inclusive Pau dos Ferros, tínhamos em 2010, nessa área, 440.877 habitantes, dos quais 281.890 (63,94\%) residiam na área urbana (IBGE, 2010). A rede urbana na região em análise apresenta irregularidades tal qual àquelas das redes urbanas do Nordeste e do Rio Grande do Norte. A região Nordeste é a que detém o maior número de municípios com menos de 50 mil habitantes, 1.631 dos 1.793 municípios, o que equivale a mais de $90 \%$ dos municípios nordestinos. No Rio Grande do Norte, essa situação se agrava, 101 dos 167 municípios têm menos de 10 mil habitantes, e apenas 27 municípios tem mais de 20 mil habitantes. (IBGE, 2010)

Essa fragmentação da rede urbana somada à ampliação da oferta dos serviços de educação de nível superior e saúde tanto no âmbito público como privado, bem como a diversidade do comércio tem atraído pessoas de outros municípios e da área rural em busca de emprego urbano, o que aumentou a mobilidade pendular de pessoas para Pau dos Ferros. 
Revista Tecnologia e Sociedade, Curitiba, v. 11, n. 23, 2015

ISSN (versão online): 1984-3526

ISSN (versão impressa): 1809-0044

\section{A interiorização dos serviços públicos (educação superior e saúde) e sua repercussão na dinâmica regional.}

A saída dos jovens do interior para estudar na capital tem sido quase uma regra em todo o país, tratando-se de cidades do interior do Nordeste, essa realidade é ainda mais grave. No Rio Grande do Norte, em 2010, Natal ainda concentrava, $70 \%$ das matrículas em cursos presenciais (BRASIL, 2010).

A despeito dessa concentração houve crescimento significativo dos alunos matriculados no interior. Parte deste crescimento se deu através da expansão da UERN, ocorrida a partir de 2003, com a ampliação de vagas através da criação de novos Campi e novos cursos e de 11 (onze) Núcleos Avançados em diversas regiões do estado.

Desde sua criação e até o início dos anos 2000, o Campus de Pau dos Ferros oferecia regularmente três cursos de graduação (Ciências Econômicas, Letras e Pedagogia), com a oferta média de 140 vagas anuais. Durante esse período, os cursos de graduação do Campus de Pau dos Ferros, posteriormente denominado, Campus Avançado "Profa. Maria Elisa de Albuquerque Maia" (CAMEAM) ${ }^{9}$ foram a única opção de ingresso na educação superior para os jovens do Alto Oeste Potiguar, e, também, dos municípios fronteiriços da Paraíba e do Ceará, o que explica sua abrangência regional desde o início de suas atividades nos anos 1970.

Em 2003, a criação de 04 (quatro) cursos de graduação no Campus da UERN, em Pau dos Ferros, trouxe não apenas novo fôlego para aquele Campus, mas também contribuiu para dinamizar a economia local e ampliar sua área de atuação. O mercado imobiliário e os setores de alimentação e hospedagem foram os mais beneficiados. Além da ampliação dos alunos, 577 alunos em 2003, para 1522, em 2010, Dantas (2014) mostra que o número de servidores docentes e técnicos passa de 58, em 2000, para 229, em 2010. Esse quadro 'novo' era quase todo proveniente de outros centros, com destaque para Natal, Mossoró e Fortaleza, o que acentuou a procura por moradias e fez com que os preços dos alugueis superassem os índices inflacionários, bem como aumentou a procura nos hotéis e pousadas da cidade, ampliou-se também a procura por terrenos, e, por conseguinte, o preço desses terrenos, em especial, dos que ficavam mais próximos à universidade.

\footnotetext{
${ }^{9}$ No decorrer deste texto, serão utilizadas as duas formas.
} 
Revista Tecnologia e Sociedade, Curitiba, v. 11, n. 23, 2015

ISSN (versão online): 1984-3526

ISSN (versão impressa): 1809-0044

Atualmente o Campus de Pau dos Ferros, além da graduação, conta com 04 (quatro) programas de pós-graduação stricto sensu que oferecem 04 cursos de mestrados e 01 de doutorado, tornando-se Pau dos Ferros a menor cidade do Brasil, em dimensão populacional, a oferecer um Curso de Doutorado.

A atuação regional do Campus de Pau dos Ferros pode ser entendida quando verificamos as matrículas por município. Dos 1803 alunos matriculados nos cursos de graduação do CAMEAM, em 2012, apenas 461 (25\%) eram de Pau dos Ferros. Atualmente, são mais de 70 munícipios que enviam alunos apenas para os cursos de graduação do CAMEAM.

A centralidade de Pau dos Ferros também ocorre na oferta dos serviços de saúde. O fato de Pau dos Ferros ter atuado desde o início do processo de regionalização (1975) como polo regional de saúde do Alto Oeste Potiguar já demonstra sua atuação regional em termos de prestação dos serviços saúde pública. A construção do hospital regional Dr. Cleodon Carlos de Andrade, inaugurado em 1990, vem reforçar essa polaridade e ampliar, inclusive sua área de atuação. Além do HCCA, existem em Pau dos Ferros outras unidades de saúde públicas e privadas, totalizando 71 unidades, sendo 21 públicas e 50 privadas.

Dantas (2014) aponta que houve, em 2010, 154.495 atendimentos ambulatoriais com registro de município de origem, dos quais pouco mais da metade $(54,78 \%)$ tiveram origem no próprio município, os demais atendimentos foram de pessoas que residem em outros 56 munícipios do Rio Grande do Norte, e de municípios fronteiriços. Já as internações nas unidades de saúde de Pau dos Ferros contabilizaram em 2010, 4.634, das quais menos de 1/3 são provenientes de Pau dos Ferros.

\section{A mobilidade pendular na região: uma análise dos fluxos populacionais para trabalho e estudo}

Estudos recentes na área urbana e regional tem apontado o fenômeno da mobilidade pendular como elemento central para compreensão das dinâmicas de integração urbana. De acordo com Moura (2009), os movimentos pendulares estão associados a mudanças socioeconômicas e são apontados como uma expressão da reestruturação do trabalho e do capital com implicações na estrutura urbana, na circulação de pessoas, as vias de acesso e aos transportes. 
Revista Tecnologia e Sociedade, Curitiba, v. 11, n. 23, 2015

ISSN (versão online): 1984-3526

ISSN (versão impressa): 1809-0044

Em termos de fluxo de pessoas que realizam movimento pendular, Pau dos Ferros assume o 11일 lugar no Estado em 2010, passa de 1.511 pessoas em 2000 para $4.987 \mathrm{em}$ 2010. A maior parte deste crescimento aconteceu na entrada de pessoas $(77,44 \%)$ do fluxo, o que o caracteriza como um município receptor de pessoas; interessante ressaltar que em 2010, Pau dos Ferros foi responsável por $20,28 \%$ das entradas em sua área de influência, em 2000 este percentual era de $16,17 \%{ }^{10}$.

Tomando os municípios que compõe a área de influência de Pau dos Ferros observamos que os maiores fluxos de saída em 2010 ocorreram nos municípios de Apodi (RN) e Catolé do Rocha (PB), com participações de 8,78\%, 6,0\%; em termos de fluxos de entrada, Pau dos Ferros se destaca com $20,28 \%$ dos fluxos.

Importante também verificar a proporção dos fluxos em relação à população que trabalha e a população que estuda. Tomando como polo, o município de Pau dos Ferros, Dantas (2014) fez uma seleção dos municípios que tiveram em 2010 fluxos de destino de mais de 50 pessoas para Pau dos Ferros e observou que à exceção da cidade em estudo, todos os demais municípios têm taxa de mobilidade (saída) superior à taxa de atração (entrada), o que corrobora a hipótese de que Pau dos Ferros ao atuar como centro de serviços atrai estudantes e trabalhadores de uma quantidade significativa de municípios o que acentua seu papel de intermediação para além do Alto Oeste Potiguar.

Por outra perspectiva, os dados permitem verificar que a grande maioria dos municípios não dispõe dos serviços básicos para atendimento a população em idade de estudar, nem dispõe de atividades econômicas capazes de assegurar emprego à população economicamente ativa, o que justifica que 13 (treze) dos 20 (vinte) municípios tenham índices proporcionais de saída para trabalho em relação à população ocupada superiores a 10\%, (18,1 em Francisco Dantas e 17,7 em Rafael Fernandes).

Importante ressaltar que a atratividade que Pau dos Ferros representa em termos de oferta de trabalho, decorre também da oferta de melhores salários: $27 \%$ dos que trabalham em Pau dos Ferros recebem até um salário mínimo, nos demais municípios mais de $40 \%$ dos ocupados estão nessa faixa; entre ao que recebem

\footnotetext{
${ }^{10}$ Os dados do movimento pendular tem como fonte os microdados da Amostra dos Censos do IBGE de 2000 e 2010, compilado por Dantas (2014).
} 
Revista Tecnologia e Sociedade, Curitiba, v. 11, n. 23, 2015

ISSN (versão online): 1984-3526

ISSN (versão impressa): 1809-0044

mais de 5 salários mínimos, 15\% dos que trabalham em Pau dos Ferros, e apenas $4,8 \%$ dos que trabalham em outros municípios.

Dantas (2014) elaborou uma matriz origem-destino dos 56 municípios que compõe a área de estudo, o que permitiu separar os movimentos internos, dos demais deslocamentos das pessoas que residem na área em epígrafe, e verificar a origem e o destino dos deslocamentos, ou seja, o sentido dos fluxos.

Os deslocamentos dentro da área de influência totalizam 11.592, sendo 6.596 (56,9\%) para estudo e 4.996 (43,09\%) para trabalho. Como era de esperar, Pau dos Ferros recebe $29,03 \%$ do fluxo de pendularidade da sua área de influência. Já os principais municípios de origem são Apodi com 7,08\% e São Miguel (3,89\%).

Dantas (2014) usou alguns indicadores tradicionalmente utilizados para 0 estudo de fluxos migratórios que possibilitará apreender não apenas o peso absoluto, mas também o peso relativo que essas pessoas possuem sobre o volume total da população residente no município ${ }^{11}$, são eles: a taxa líquida de pendularidade ajuda a entender o impacto que as entradas de deslocamentos pendulares causam no total populacional do município; o índice de eficácia da pendularidade (IEPend) informa a posição de cada município em termos de sua capacidade de oferecer ou atrair mão-de-obra e varia de -1 (alta expulsão) a 1 (alta atração), sendo os valores muito próximos a zero considerados como áreas de circulação. A tabela 1 traz alguns indicadores de mobilidade pendular entre os municípios da área de influência de Pau dos Ferros ${ }^{12}$.

\begin{tabular}{|c|c|c|c|c|c|c|}
\hline Município & Saída & Entrada & $\begin{array}{l}\text { Saldo } \\
\text { pendular }\end{array}$ & $\begin{array}{l}\text { Pendularidade } \\
\text { bruta }\end{array}$ & $\begin{array}{l}\text { Taxa pend } \\
\text { líquida }\end{array}$ & IEPend \\
\hline Pau dos Ferros-RN & 388 & 3366 & 2978 & 3754 & 10.73811 & 0.793287 \\
\hline Apodi-RN & 821 & 378 & -443 & 1199 & -1.27383 & -0.36947 \\
\hline São Miguel-RN & 451 & 409 & -42 & 860 & -0.18954 & -0.04884 \\
\hline Patu-RN & 160 & 631 & 471 & 791 & 3.93681 & 0.595449 \\
\hline Catolé do Rocha-PB & 249 & 528 & 279 & 777 & 0.972125 & 0.359073 \\
\hline Uiraúna-PB & 368 & 326 & -42 & 694 & -0.28799 & -0.06052 \\
\hline Umarizal-RN & 268 & 408 & 140 & 676 & 1.312213 & 0.207101 \\
\hline Pereiro-CE & 309 & 334 & 25 & 643 & 0.160442 & 0.03888 \\
\hline Alexandria-RN & 318 & 306 & -12 & 624 & -0.08905 & -0.01923 \\
\hline Itaú-RN & 301 & 302 & 1 & 603 & 0.01796 & 0.001658 \\
\hline
\end{tabular}

11 Ojima e Marandola Jr (2012) utilizaram essa análise como forma de apreender a importância dos deslocamentos pendulares mesmo fora das regiões metropolitanas, como é o caso desse estudo.

12 Tendo em vista a dimensão da área de influência (55 municípios), foram selecionados os 10 municípios com os maiores fluxos. 
Revista Tecnologia e Sociedade, Curitiba, v. 11, n. 23, 2015

ISSN (versão online): 1984-3526

ISSN (versão impressa): 1809-0044

\begin{tabular}{l|r|r|r|r|r|r}
\hline Total $10+$ & 3633 & 6988 & 3355 & 10621 & 1.811447 & 0.315884 \\
\hline Demais Municípios & 7959 & 4604 & -3355 & 12563 & -1.31042 & -0.26705 \\
\hline
\end{tabular}

Tabela 1 - Indicadores de mobilidade pendular para trabalho e estudo - Área de Influência de Pau dos Ferros (2010). Fonte: IBGE (2010 apud Dantas 2014, p. 228). Notas: 1) Taxa líquida de pendularidade $=$ quociente do saldo pendular pelo total populacional $(\mathrm{em} \%)$. 2) IEPend $=$ Quociente entre 0 saldo pendular e a pendularidade bruta.

Pau dos Ferros se confirma como o grande receptor de fluxos de sua área de influência em todos os indicadores apresentados. Com IEPend de 0,79 confirma seu poder de atração de pessoas para trabalho e estudo. Como município expulsor, identificamos Apodi (RN) com IEPend $(-0,36)$, o que pode decorrer de sua localização de proximidade e facilidade de locomoção (BR 405) tanto com Pau dos Ferros, como com Mossoró, segunda cidade do Estado. Os demais municípios apresentaram IEPend próximos a zero, e, portanto podem ser considerados como municípios de rotatividade pendular.

Como parâmetro de agrupamento para apresentar o direcionamento dos fluxos, Dantas (2014) utilizou o modo de distribuição por quantil ${ }^{13}$ dividido em 5 partes. A análise foi feita para os fluxos de trabalho (mapa 3) e estudo (mapa 4).

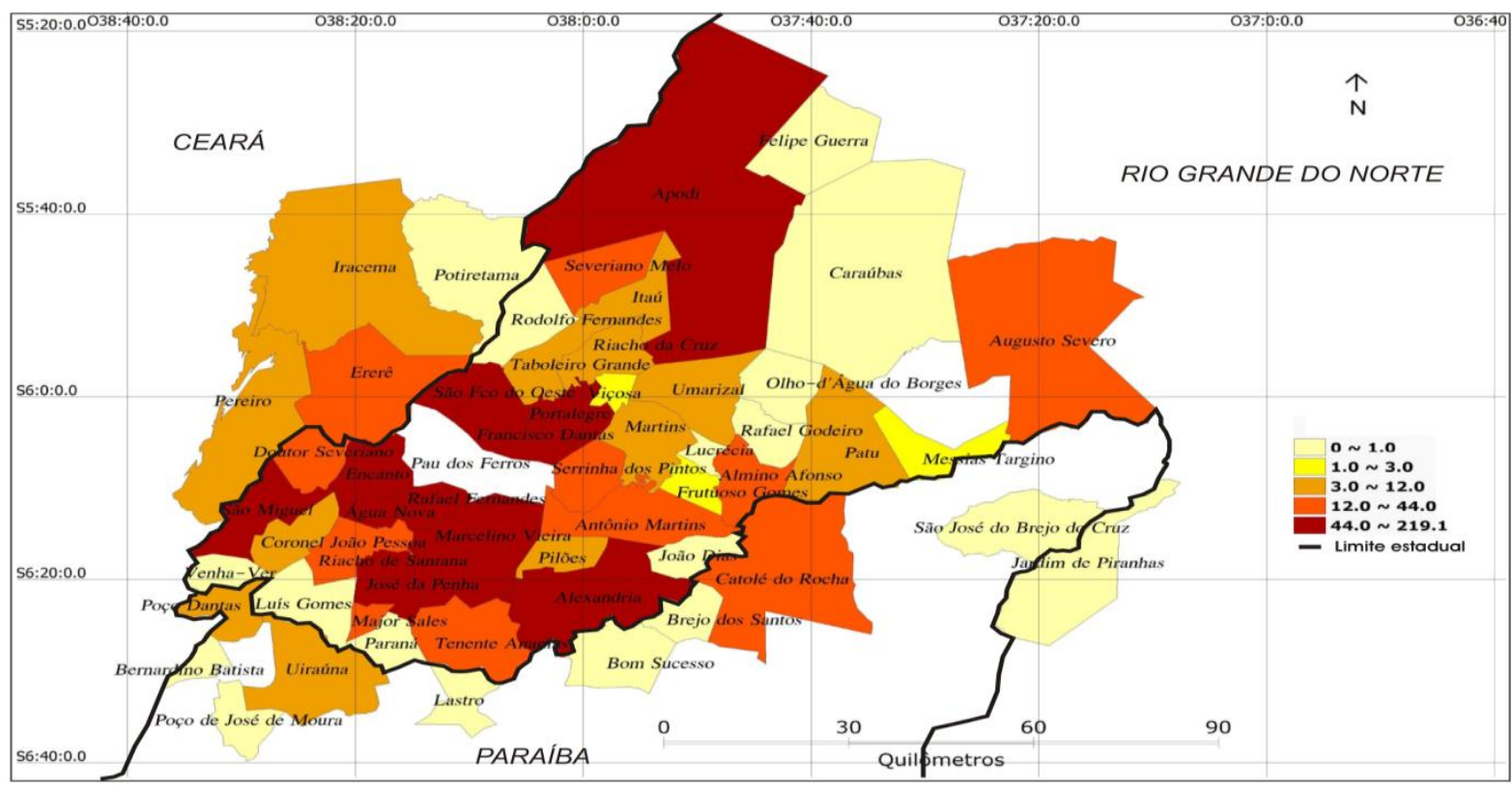

Mapa 3 - Fluxos pendulares de pessoas para trabalho em Pau dos Ferros - 2010 (por quintil) Fonte: Dantas (2014, p. 231).

Os $20 \%$ dos municípios com maiores fluxos de pessoas para trabalho (mapa 3) são compostos por aqueles fazem fronteira física com Pau dos Ferros e estão em

\footnotetext{
${ }^{13}$ Essa operação foi realizada no terraview, sendo escolhido o modo quantil, o qual divide as classes conferindo a cada classe o mesmo número de ocorrências em cada uma delas.
} 
Revista Tecnologia e Sociedade, Curitiba, v. 11, n. 23, 2015

ISSN (versão online): 1984-3526

ISSN (versão impressa): 1809-0044

uma média de $20 \mathrm{~km}$ de distância, chegam a formar uma espécie de 'círculo' ao redor do município. São municípios pequenos, com população inferior a 10 mil habitantes e quase nenhuma atividade econômica própria. A exceção fica por conta dos municípios de Alexandria e São Miguel localizados a distância de 50 km e Apodi localizado a $75 \mathrm{~km}$ de Pau dos Ferros, considerados pelo Regic, Centros de zona. Ambos têm o comércio e o setor de serviços relativamente desenvolvidos e dispõem de agências bancárias, além de disporem de oferta de ensino superior público.

Os municípios que formam o segundo quintil estão localizados nos arredores dos municípios que formam o primeiro quintil, neste grupo se encontram também os municípios de Ererê (CE) e Catolé do Rocha (PB).

Os três últimos quintis tem formação mista com participação dos municípios do Ceará (Iracema e Pereiro) e da Paraíba (Uiraúna e Poço Dantas), mas também de vários municípios potiguares, com destaque para Umarizal e Patu.

O mapa 4 que mostra o fluxo das pessoas que se deslocam para estudo em Pau dos Ferros também mostra que os $20 \%$ que mais enviam estudantes se concentram nos municípios mais próximos, com a inclusão dos municípios de Doutor Severiano (RN) e Pereiro (CE). Já os municípios de Alexandria e Apodi, que estão entre os $20 \%+$ no fluxo de trabalho, saíram do primeiro quintil, no caso de Apodi, está entre os $20 \%$ que menos enviam pessoas para estudo em Pau dos Ferros. Cremos que essa diferença se deve ao fato destes municípios disporem de pelo menos uma instituição de ensino superior, e no caso de Apodi, tem também a proximidade com Mossoró. 
Revista Tecnologia e Sociedade, Curitiba, v. 11, n. 23, 2015

ISSN (versão online): 1984-3526

ISSN (versão impressa): 1809-0044

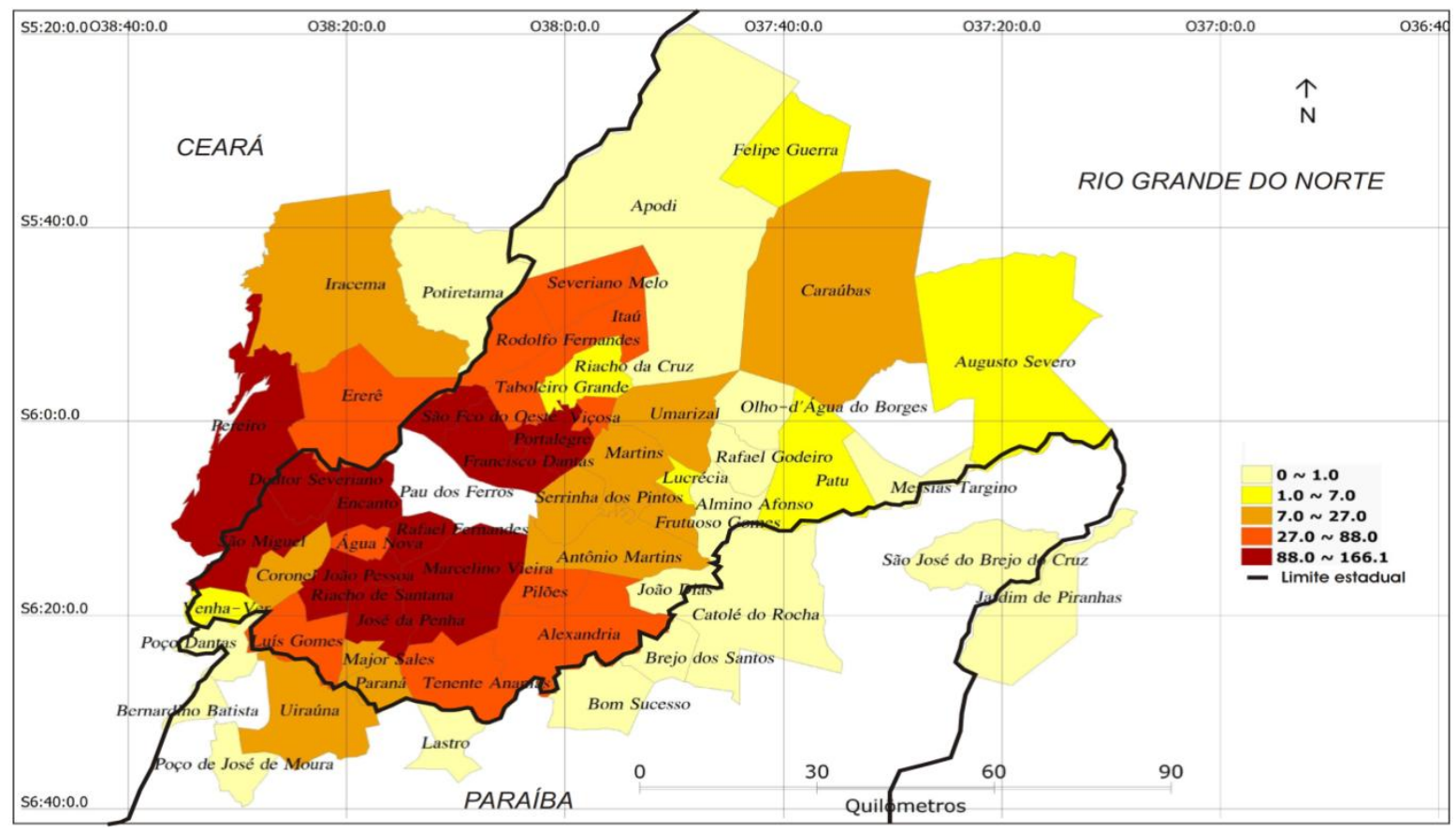

Mapa 4 - Fluxos pendulares de pessoas para estudo em Pau dos Ferros - 2010 (quintil) Fonte: Dantas (2014, p. 232).

No segundo e terceiro quintis, predominam municípios pequenos, localizados a uma distância média de $50 \mathrm{~km}$, e que não dispõem de instituições públicas de ensino superior, à exceção de Alexandria. Os dois últimos quintis que representam os $40 \%$ que menos enviam estudantes a Pau dos Ferros ficam a uma distância superior a 70 km e alguns como Apodi (RN) e Catolé do Rocha (PB), já dispõem de oferta de ensino superior.

Esses dados corroboram nossa tese inicial de que Pau dos Ferros assume as funções de uma cidade média, especialmente no que se refere à oferta de serviços de educação e trabalho no interior da 'rede urbana nordestina interiorizada', em especial na raia divisória $\mathrm{RN}-\mathrm{PB}-\mathrm{CE}$.

\section{CONSIDERAÇÕES FINAIS}

Este trabalho partiu da premissa que em virtude da fragmentação da rede urbana nordestina e de sua dupla dinâmica, expressa na concentração das metrópoles e grandes centros no litoral e na existência de poucos centros no interior, alguns polos regionais tem assumido as funções de uma cidade média, sem, contudo, apresentar todas as características para tal. Referimo-nos aqui a existência 
Revista Tecnologia e Sociedade, Curitiba, v. 11, n. 23, 2015

ISSN (versão online): 1984-3526

ISSN (versão impressa): 1809-0044

de atividades terciárias como comércio, transportes, armazenagem, habitação, cultura e finanças, mas referimo-nos também a oferta de serviços de saúde de média complexidade e educação superior e técnica. A centralidade desses serviços tem possibilitado também a oferta de empregos para a população da região, inclusive emprego de mão-de-obra qualificada como nos casos da saúde e da educação.

É o caso de Pau dos Ferros, no Rio Grande do Norte. Encravado no interior do estado potiguar, na raia divisória do Rio Grande do Norte-Paraíba-Ceará, Pau dos Ferros assume o papel de intermediação entre os grandes centros e os 55 municípios que compõem sua área de influência.

Consideramos a existência do ensino superior na cidade desde os anos 1970, e sua expansão, a partir da década de 2000 , inicialmente na rede pública e posteriormente na rede privada, como um diferencial para a configuração urbanoregional de Pau dos Ferros. Tomando os municípios de origem dos alunos matriculados no Campus da UERN, em Pau dos Ferros, tinhamos em 2012, apenas $25 \%$ dos alunos matriculados de Pau dos Ferros, os demais pertenciam a outros 64 municípios do Rio Grande do Norte, da Paraíba e do Ceará;

Essa mesma centralidade pode ser observada se tomarmos como referência a prestação dos serviços de saúde, no qual mais de $40 \%$ dos atendimentos registrados pela Secretaria Municipal de Saúde são de outros 56 municípios.

Essa movimentação diária de pessoas para Pau dos Ferros também foi ressaltada pelos dados da mobilidade pendular apresentados pelo IBGE referentes ao fluxo de pessoas para trabalho e estudo. Além do volume do fluxo e de sua participação na população ocupada e na população estudante, nos quais Pau dos Ferros apresentou altos percentuais de participação dos fluxos de entrada para trabalho $(16,7)$ e dos fluxos de entrada para estudo $(26,3)$, os indicadores de mobilidade pendular para trabalho e estudo, com destaque para o IEpend de 0,79, apontou Pau dos Ferros como o grande receptor de fluxos da sua área de influência.

É como se tivesse surgindo no interior da rede urbana nordestina, um novo tipo de cidade formado por centros sub-regionais que em virtude da recente interiorização dos serviços públicos, tem conseguido atrair investimentos privados nessas áreas, o que tem contribuído para dinamizar sua economia interna, bem como ampliar sua área de influência. Como exemplos, podemos citar, além de Pau 
Revista Tecnologia e Sociedade, Curitiba, v. 11, n. 23, 2015

ISSN (versão online): 1984-3526

ISSN (versão impressa): 1809-0044

dos Ferros no Rio Grande do Norte, as cidades de Cajazeiras e Sousa na Paraíba; as três na raia divisória RN-PB-CE, mas também Patos (PB), Garanhuns (PE), Picos (PI) entre outras.

Essas cidades têm assumido funções de intermediação na rede urbana do Nordeste, especialmente na oferta de ensino superior e saúde, além da oferta de empregos no comércio e nos serviços públicos e privados; são cidades integradas e/ou com possibilidades de integração à dinâmica da urbanização regional, podendo, portanto, serem consideradas "cidades médias" ou "cidades intermediárias".

Para tanto, porém, faz-se necessário que os investimentos federais e estaduais em educação, considerados estratégicos para o desenvolvimento regional, continuem a ser descentralizados e direcionados para esses centros do interior. Fazse necessário também que os investimentos em saúde sejam, de fato, descentralizados, com a aquisição de equipamentos de ponta que permitam uma regionalização da saúde, não apenas nos procedimentos mais simples, mas também nos procedimentos de média e alta complexidade.

Mais saúde, mais educação, mais transporte, mais cultura, mais cidadania! Mais qualidade de vida! Para isso, torna-se necessária uma integração entre as políticas públicas e a ampliação em escala nacional de políticas sociais, diga-se, universalizadas. Na mesma medida, é imprescindível o Estado colocar no centro, como prioridade, uma política consistente de emprego e renda, que consolide as atuais ações voltadas ao crescimento de postos formais de trabalho, dando garantia mínima a muitos brasileiros. Por fim, criar novas políticas que atendam de fato às demandas locais, embasadas nas particularidades de cada região, próprias da heterogeneidade regional em nosso país, que possam se não eliminar, minimizar, a desigualdade regional, social e econômica, já que esta é uma característica intrínseca ao sistema capitalista.

\section{REFERÊNCIAS}

AMORIM FILHO, O.; SERRA, R.V. Evolução e perspectivas do papel das cidades médias no planejamento urbano e regional. In: ANDRADE, T. A.; SERRA, R. V. Cidades médias brasileiras. Rio de Janeiro: IPEA, 2001. p. 1-34. 
Revista Tecnologia e Sociedade, Curitiba, v. 11, n. 23, 2015

ISSN (versão online): 1984-3526

ISSN (versão impressa): 1809-0044

ANDRADE, M. C. Espaço, polarização e desenvolvimento: a teoria dos polos de desenvolvimento e a realidade nordestina. 3aㅡ ed. São Paulo: Brasilense, 1973.

ANDRADE, M. C. Geografia econômica do Nordeste: o espaço e a economia nordestina. São Paulo: Atlas, 1987.

ARAÚJO, L. A.; LIMA, J.P. R. Transferências de renda e empregos públicos na economia sem produção do semiárido nordestino. Planejamento e políticas públicas, Rio de Janeiro, n. 33, p. 45-77, jul./dez., 2009.

ARAÚJO, M. M. S.; MOURA, R.; DIAS, P. C. Cidades Médias: uma categoria em discussão. In: PEREIRA, R.H. M.; FURTADO, Bernardo A. (Org.). Dinâmica urbano-regional: rede urbana e suas interfaces. Brasília: IPEA, 2011. p. 61-77.

BRANDÃO, C. Território e desenvolvimento: as múltiplas escalas entre o local e o global. Campinas: Editora da UNICAMP, 2007.

BRASIL. Censo da educação superior: 2010. Brasília: Instituto Nacional de Estudos e Pesquisas Educacionais Anísio Teixeira, 2010.

CANO, W. Urbanização: sua crise e revisão de seu planejamento. Revista de Economia Política, São Paulo, v. 9, n 1, p. 62-82, jan./mar. 1989.

CANO, W. Desequilíbrios regionais e concentração industrial no Brasil (1930-1995). Campinas: Editora da Unicamp, 1998.

DANTAS, J. R. Q. As cidades médias no desenvolvimento regional: um estudo sobre Pau dos Ferros (RN). Natal, 2014, 260p. Tese (Doutorado em Ciências Sociais) Programa de Pós-Graduação em Ciências Sociais, Universidade Federal do Rio Grande do Norte, 2014.

DANTAS, J. R. Q.; CLEMENTINO, M. L. M. O papel das cidades (inter) médias para o desenvolvimento regional: um estudo a partir dos centros sub-regionais (Pau dos Ferros-RN, Cajazeiras-PB e Sousa-PB). GeoUERJ, Rio de Janeiro, ano 15, n. 24, v.1, p. 228-255, 1. sem. 2013.

FARIA, V. O processo de urbanização no Brasil: algumas notas para seu estudo e interpretação. In: Encontro da Associação Brasileira de Estudos Populacionais, 1, 1978. Anais..., p. 89-110, 1978.

FERRÃO, J.; HENRIQUES, E. B.; NEVES, A. O. Repensar as cidades de média dimensão. Análise Social, Lisboa, v. XXIX, p. 1123-1147, 1994.

GOMES, G. M. Velhas secas em novos sertões: continuidade e mudanças na economia do semi-árido e dos cerrados nordestinos. Brasília: IPEA, 2001.

IBGE - Instituto Brasileiro de Geografia e Estatística. Região de Influência das Cidades 2007. Rio de Janeiro: IBGE, 2008.

IBGE - Instituto Brasileiro de Geografia e Estatística. Censo demográfico 2010. Rio de Janeiro: IBGE, 2010.

IPEA - Instituto de Pesquisa Econômica Aplicada. Caracterização e tendências da rede urbana no Brasil - Redes urbanas regionais: Norte, Nordeste e Centro Oeste. (vol. 4). Brasília: IPEA, IBGE, UNICAMP, 2002. 
Revista Tecnologia e Sociedade, Curitiba, v. 11, n. 23, 2015

ISSN (versão online): 1984-3526

ISSN (versão impressa): 1809-0044

MOURA, R. Arranjos urbano-regionais no Brasil: uma análise com foco em Curitiba. Curitiba, 242p. Tese (Doutorado em Geografia) Programa de Pós-Graduação em Geografia, Universidade Federal do Paraná, 2009.

OJIMA, R.; MARANDOLA JR, E. Mobilidade populacional e um novo significado para as cidades: dispersão urbana e reflexiva na dinâmica regional não metropolitana. Revista Brasileira de Estudos Urbanos e Regionais, Rio de Janeiro, v.14, n. 2, p 103-116, 2012.

PEREIRA, A. M. Cidade média e região: o significado de Montes Claros no norte de Minas Gerais. Uberlândia, 2007, 351p. Tese (Doutorado em Geografia) Programa de PósGraduação em Geografia, Universidade Federal de Uberlândia, 2007.

SIMÕES, R.; AMARAL, P. V. Interiorização e novas centralidades urbanas: uma visão prospectiva para o Brasil. Revista Economia, Brasília, v. 12, n. 3, p. 553-579, set./dez. 2011.

SPOSITO, M. da E. B. As cidades médias e os contextos econômicos contemporâneos. In: SPOSITO, M. E. B. (org.). Urbanização e cidades: perspectivas geográficas. São Paulo: UNESP, FCT, 2001. p. 609-643.

TORNÉ, J. M. L.; SANFELIU, C. B. Comentários sobre algunos resultados de las escuestas en el programa UIA-CIMES. 2000. 5.p. (Documento 6 do projeto Ciudades intermedias y urbanización mundial). Disponível em: <http://paeria.es/cimes/>. Acesso em: 03 mai. 2012. 